\title{
Selling Surveillance Technology: Semiotic themes in advertisements for ageing in place with dementia.
}

Six advertisements were explored that sell surveillance technologies for people living with dementia through qualitative content analysis.

Advertisements from the United Kingdom, Sweden and the Netherlands were analysed to explore semiotic textual meaning and people with dementia $(\mathrm{N}=5)$ and carers $(\mathrm{N}=4)$ responded to these advertisements. The semiotic themes report a "wanderer" discourse which signals to track people living with dementia, children pets and possessions. Mainly negative representations communicate the dangers of wandering towards younger-female carers, few positive representations show a smiling person with dementia and only one person was represented as interacting with technology. Participants did not understand the advertisements and people living with dementia felt stigmatised. There is a lack of reflexivity when people living with dementia are seen as objects. The reliance on stereotypes targeted at carers with misunderstood conceivable trackers hinders resilience for people living with dementia and implies the continuous stigmatisation that occurs when they are disregarded as human technology-users.

Keywords: surveillance; safety; technology; dementia; carers; advertisements; discourses; media literacy 


\section{Introduction}

Studies have highlighted the necessity to examine the representations of people living with dementia in technology advertisements and how this impacts audiences (Clarke 2006; Peel 2013; Vermeer et al. 2019a). There is an increasing interest in technological products for dementia care due to claims of; populations are ageing globally, the number of carers is decreasing, the costs of healthcare are increasing and people want to remain independently in their own homes (Neven 2010). Numerous media messages have picked up on the global challenge of dementia and wandering behaviour. Dementia is an umbrella term which includes Alzheimer's Disease (AD) being the most common one and other sub-types such as vascular dementia, fronto-temporal dementia and Lewy body (Brittain, et al. 2017). Wandering, which is mainly associated with AD, is often a feared behaviour as people living with dementia might become lost and/or hurt. An estimated 60 percent of community-dwelling individuals with $\mathrm{AD}$ will wander away at least once (Alzheimer's Association 2008; Rowe and Glover 2001; Rowe 2003). However, such statistics do not explain what type of wandering (e.g. meaningful or critical) was included and whether these numbers apply to those diagnosed with other dementias (Petonito et al. 2010). Rather, the actual risk of injury as a result of wandering is estimated to be around 5 percent (Brittain et al. 2017).

Although there continues to be a dispute about wandering and the risks, politicians, policymakers and developers are concerned about wandering and advertisers considerably sell technological products online by portraying individuals with dementia who wandered off and were found dead (Petonito et al. 2010; Carr et al. 2010; Vermeer et al. 2019a). In particular, Surveillance Technologies (STs), are often thought to be a possible solution for wandering behaviour. For example, STs such as Global Positioning Systems (GPS) and tracking devices can be used as a resilience tool to 
increase the safety and independence of people living with dementia (McCabe and Innes 2013). Notably, much debate covers the most appropriate terminology for such products as the word "surveillance" raises ethical implications and negative connotations, yet it does explain the products sold online (Vermeer et al. 2019b; 2019c). For example, there are many concerns about tracking someone whilst regarding their privacy and autonomy (Niemeijer 2015) and who received the data from the device (Kenner 2008). Nonetheless, these are commonly used technologies to locate individuals living with dementia who might wander (Rasquin et al. 2007; McCabe and Innes 2013). As a consequence of such concerns, a best practice guidance on technology and dementia has been made available from the European Union on www.dementiainduct.eu/guidance/ (INDUCT 2019) with recommendations for developers, designers, policy-makers, researchers and care-providers on how to design, implement and evaluate products. One study part of INDUCT examined websites from the United Kingdom (UK), Sweden (SWE) and the Netherlands (NL) that market ST for people living with dementia (Vermeer et al. 2019a). These three countries share similar ageing populations, policies which promote ageing in place and capacities to leverage technology for increased well-being. Most of these websites stem from small companies who employed a creative licence in advertising and claimed to be 'market leader' whilst selling re-purposed products. The purchase price ranged from free to $£ 654$, however, only few products were under $£ 10$ and it often came with additional extras (i.e. shipping costs, monthly fees). This niche market signalled people with dementia, pets and children as lost and/or wandering and kept safe through ST. These visuals and texts did not include the voices from people living with dementia, but were directed to carers (Vermeer et al. 2019a). This is problematic when money-making organisations are 
behind media discourses; yet, none have the real person at the centre of their interest (Medina 2014).

There has been considerable interest in understanding the cultural dimensions in which dementia is understood with contributions from Bosco (2019); Brookes et al. (2018); Harman and Clare (2006); Peel (2013) and Zeilig (2014). This provides a general background for the study of media discourses around the shaping of society's perception of dementia (Fuller 1998; Medina 2014). Studies have described the magnitude of culture producing meaning through discourses of ageing and dementia in cultural texts (Gilleard \& Higgs, 2000; Medina, 2014) and how our understandings about dementia, as well as those affected by them, are formed through such discourses (Clarke, 2006; Collin \& Hughes, 2011; Williamson and Skinner, 2011).

\section{Involving people living with dementia}

It is important to address questions of; how individuals living with dementia are represented in the arts, film, literature and the media and how such symbolic forms provided by popular culture can be transformed by those living with dementia in order to express their own perspectives (Swinnen and Schweda 2005). Indeed, services are increasingly involving people living with dementia, who in turn, want to influence services and policies that affect their lives (Deep 2013). Studies have looked at narrative and communication discourses from the perspective of people living with dementia (Hamilton 2008; Clare et al. 2008; Saunders et al. 2011; Saunders et al. 2012; Saunders 2017; Vermeer et al. 2020a), and person-centred approaches are increasingly focusing on looking at the person living with dementia instead of the pathology through involving them as participants (Sandberg 2018), research advisors (Vermeer et al. 2019b) or as co-author's critiquing the pathology of the "demented other" (Sabat et al. 
2011). A recent examination of the online comments from people living with dementia and family carers on STs reported that the forum included sometimes demeaning discussion about wandering (Vermeer et al. 2020a). The carers mainly discussed using ST for their peace of mind as the person with dementia became lost and/or was not able to use ST anyway. Furthermore, there was a brand awareness among carers, possibly boosted by one of the ST providers running an intensive product advertising campaign.

\section{Media literacy}

One approach to investigate media discourses and to uncover how people perceive and negotiate media messages can be uncovered through media literacy (Kellner and Share 2007). Media literacy aims to uncover signs of ideology and power and the organisations that drive the media industry (Kellner and Share 2007). Accordingly, a tripartite approach to media literacy incorporates production, semiotic textual analysis and audience reception (Lewis and Jhally 1998; Rose 2007; Thoman and Jolls 2005).

\section{Production}

Production explores context and organisations behind the advertisements of products and how these messages were circulated (Thoman and Jolls 2005). Little attention has been paid to the organisations behind media messages and the part they have in forming user representations (Akrich 1992; Latour 1992; Joyce and Mamo 2006; Neven 2010; Peel 2013; Vermeer et al. 2019a). Joyce and Mamo (2006) suggest that technology is developed with a much younger audience in mind and that older-adults (particularly older women) are not the intended user. It is important to consider the role that companies have as their advertisements might reinforce the misunderstanding of dementia, prevent social change and negatively affect technology development for 
people living with dementia (Vulpe 2017; Joyce and Mamo 2006; Peel 2013). For example, if user representations are based on stereotypes it can emerge in the work of designers and become inscripted in technology design (Akrich 1992; Latour 1992; Joyce and Mamo 2006; Neven 2010). Brankaert (2016) developed 'living labs' that involved people with dementia in various stages of the design process of diverse technologies. For example, the smartphone with a SOS-button and GPS "GoLivePhone®" was used and evaluated by ten people living with dementia and their carers by answering twice-daily questionnaires and filling in data logs. Furthermore, the device's GPS data was gathered over 2 weeks and it was concluded that STs were designed for carers and not people living with dementia (Brankaert 2016).

\section{Semiotics}

Another part of media literacy is to recognise what signs and meanings are used in advertisements through a semiotic textual approach (Lewis and Jhally 1998; Machin 2004; Kellner and Share 2007). Saussure (2011) introduced semiotics as the relationship between language and meaning through the signifier and signified. Acknowledging the relationship between signifier (e.g. literal meaning) and signified (e.g. the mental concept it represents) enables uncovering the meaning the sign represents (Saussure 2011). For example, social semiotic studies focused on dementia media discourses have examined stock images (Harvey and Brookes 2018), films (Zeilig 2014; Medina 2014), magazine and newspaper articles (Peel 2013; Kessler and Schwender 2012; Clarke 2006). Studies reported how the media mainly represent sick older women with dementia who need their dutiful female carer (Clarke 2006; Harvey and Brookes 2018). Media critics have suggested that people living with dementia are often portrayed using negative and sometimes positive stereotypes (Van Gorp and Vercruysse 2012). Table 1 
captures the negative representations of cultural themes that frame "demented" sufferers who look withdrawn, are losing their identity and humanity, invaded by the disease, a terrible destiny that awaits or call for constant care and burdens the family (Braun and Clarke 2006; Van Gorp and Vercruysse 2012; Harvey and Brookes 2018). Currently, it is unknown how and if people living with dementia are represented using technology, however older adults are often represented as not understanding technology (Joyce et al. 2015). Positive representations include portrayals of those smiling and actively living well by taking a walk to prevent dementia, have "faith in science" to find the cure or make the most of the present (“carpe diem”) (Harvey and Brookes 2018; Sweeting and Gilhooly 1997; Peel 2013; Van Gorp and Vercruysse 2012). However, both representations may negatively impact a person's health and personhood as it does not construct reality or the challenges people face and consequently the person dissapears behind the diagnosis (Minichiello et al. 2000; Van Gorp and Vercruysse 2012; Kessler and Schwender 2012).

Table 1 negative and positive representations

\begin{tabular}{|c|c|}
\hline Negative representations & Positive representations \\
\hline $\begin{array}{l}\text { - } \quad \text { "Demented Sufferers" } \\
\text { - } \quad \text { Look withdrawn call for constant care } \\
\text { - } \quad \text { Invaded by disease } \\
\text { - Terrible destiny awaits } \\
\text { - Not understanding technology }\end{array}$ & $\begin{array}{ll}\text { - } & \text { Smiling } \\
\text { - } & \text { Actively living well } \\
\text { - } & \text { Taking a walk to prevent dementia } \\
\text { - } & \text { Faith in science } \\
\text { - } & \text { Carpe diem }\end{array}$ \\
\hline
\end{tabular}

*Dichotomy created by the authors by summarising work from Sweeting and Gilhooly 1997; Minichiello et al. 2000; Braun and Clarke 2006; Kessler and Schwender 2012; Van Gorp and Vercruysse 2012; Peel 2013; Joyce et al. 2015; Harvey and Brookes 2018) 
However, audiences might interpret these meanings differently or in a way that retains 'the institutional political/ideological order imprinted on them' (Hall 1980: 134). Audience reception of media messages happens according to Hall (1980) in accordance with a dominant, negotiation or oppositional position. The dominant position is where audiences accept the message as common sense and with the negotiated position they relatively agree but also challenge the message. The oppositional position is taken when audiences reject the message. How audience respond and the examination of semiotics by exploring the social construction of how media is produced, enables uncovering the social and power relations present in discourses (Hall 1973, 1980).

Withal, the cultural contexts in which advertisements are produced might offer insights about the relationships between technology, dementia discourse and the interests of organisations (Fuller 1998; Clarke 2006; Joyce and Mamo 2006). Although some research has been carried out on dementia discourses (Birt et al. 2017; McParland et al 2017), no study has been found which examined technology advertisements with questions of production, textual semiotics and audience reception. This study looks at the interplay between ST messages and audiences and is aware of the wider discussion available on media messages connected to dementia and ageism. Its primary purpose is to present the study and reflect on what it means for this discourse and market.

\section{Method}

The advertisements were subjected to qualitative content analysis as analytical constructs investigated through theory-driven coding from previous research was employed (Downe-Wamboldt 1992). Attention was paid to look for other themes that might provide alternative findings to those suggested by literature. 


\section{Selecting advertisements}

The first author carried out the search for advertisements using the Google search engine in January 2018. Search terms (Surveillance technology, Surveillance technologies, devices, products, assistive, GPS, tracking, tagging, tracker, track, monitor, locate, locator, Dementia Alzheimer, Alzheimer's, person with dementia, people with dementia, Carer informal caregiver, caregiver, Family caregiver, family carer, UK, England, Great Britain, Nederland, Sverige, AND [...] OR Safety, independence, empowerment, risk, danger, alert, peace of mind, consent, informed consent, wandering, lost and fall) from Vermeer and colleagues (2019a) were used. The word "advertisements" was added with equivalent translated synonyms (e.g. commercial, flyer, communication, endorsement, poster, video, film). The websites were ranked according to Google's "most relevant results", "last updated up to a year ago" and screened for information. Websites with at least two of the keywords were selected for further analysis to ascertain that the study includes discourses that are most common and likely found by audiences.

\section{Analysis of the advertisements}

The method was guided by employing the theoretical frameworks of Hall $(1973,1980)$ and Saussure (2011) which offered a critical discourse approach to semiotic analysis. Websites were then searched based on the presence of (1) older adults as main and/or secondary actors with reference to dementia, (2) products that are technological and track and (3) a combination of factors (e.g. grey hair, wrinkles, walking aids) and (4) stem from the UK, SWE or NL. For the purposes of the analysis, dichotomous categories as summarised in table 1 have been created, however, in practice such binary 
distinctions are unusual and contextualised. To provide a cleared basis for understanding the tensions that exist, these distinctions have been drawn out in Table 2 . Then the sample was reviewed and audio from the films were transcribed and translated. The semiotic analysis was extended by exploring the represented actors, signifiers and narrative summaries were made to determine the dominant discourse (Hall 1973,1980; Saussure 2011). After initial summarising and coding, two independent researchers (SW\&SG) active in the area of dementia and technology were consulted and asked to respond to the analysis results. The two independent researchers were provided with a media literacy kit inspired by Thoman and Jolls (2005). This kit serves as a guide to apply media literacy by asking five key questions 1) who created this message 2) What techniques are used to attract my attention? 3) How might different people understand this message differently from me? 4) What lifestyles, values and points of view are represented in, or omitted from, this message? 5) Why was this message sent. The two independent researchers were hereby enabled to code independently and a discussion with the first author followed during which divergences were discussed. In particular, the films were more susceptible to different interpretations depending on the context in which they were used. This phase lasted until the researchers reached a saturation point when no new portrayals and signs were detected. Hereby a visual and textual analysis of each advertisement was completed to establish the operative signifiers and determine the dominant discourse encoded on the basis of established methods from the semiotics researchers reported in table 1 and according to seminal authors Hall $(1973,1980)$ and Saussure (2011). For production, the first author explored the websites and examined the organisation's size and country origin. Where possible, public information about the organisation's financial status was sought. The findings from the content analysis were triangulated by consultations with the three 
authors, the two independent researchers, and focus group participants to enhance credibility (Lincoln and Guba 1985).

\section{Collecting and analysing audience response}

The focus groups received ethical approval from the university review board and were conducted in collaboration with Alzheimer "Nederland" in the Netherlands in June and September 2018. The sample included a group of four female carers and one group of four males and one female living with dementia. The first author led the discussions and a member of Alzheimer Netherlands participated and took notes. The full procedure can be found elsewhere (Vermeer et al. 2020b). Participants were presented with a film and asked about their initial reaction followed by a short discussion. Then participants were asked to respond to visuals of happy older adults, children and pets (number 4 and 5 in table 2) followed by older adults fallen down and/or lost (number 6 in table 2). To further validate these interpretations, the three authors' discussed these resultsadjustments were made accordingly and compared with the participants' responses. The participants were sent these results and asked to comment. In June 2019 the first author reviewed the sample's organisation size and financial status to account for any occurring changes. 


\section{Results}

Table 2 dichotomous categories

\begin{tabular}{|c|c|c|c|c|c|}
\hline 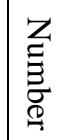 & $\stackrel{8}{\stackrel{g}{g}}$ & Discourse & Brand & Representations & $\begin{array}{l}\text { Signifier and } \\
\text { signified }\end{array}$ \\
\hline 1 & $\sum_{\pi}^{\infty}$ & Youtube film & SafetyOldCard $^{1}$ & $\begin{array}{l}\text { Older woman } \\
\text { Older male }\end{array}$ & $\begin{array}{l}\text { Lost/Wandering } \\
\text { Withdrawn and call } \\
\text { for constant care } \\
\text { Fallen } \\
\text { Terrible destiny } \\
\text { awaits }\end{array}$ \\
\hline 2 & $\sum_{\pi}^{\infty}$ & Youtube film & The family & $\begin{array}{l}\text { Family- } \\
\text { members } \\
\text { Older women } \\
\text { Children, pets, } \\
\text { possessions }\end{array}$ & $\begin{array}{l}\text { Lost/Wandering } \\
\text { Withdrawn }\end{array}$ \\
\hline \multirow{2}{*}{3} & \multirow{2}{*}{ Z } & Youtube film & Carebelt $^{2}$ & $\begin{array}{l}\text { Older male } \\
\text { Younger-alarm } \\
\text { centre employee }\end{array}$ & $\begin{array}{l}\text { Lost/Wandering } \\
\text { Withdrawn and call } \\
\text { for constant care } \\
\text { Using technology }\end{array}$ \\
\hline & & $\begin{array}{l}\text { Visuals print } \\
\text { advertisement }\end{array}$ & Carebelt & $\begin{array}{l}\text { Younger carer } \\
\text { and older } \\
\text { women }\end{array}$ & $\begin{array}{l}\text { Withdrawn and call } \\
\text { for constant care } \\
\text { Terrible destiny } \\
\text { awaits }\end{array}$ \\
\hline 4 & $\stackrel{\subseteq}{\mathbb{\lambda}}$ & $\begin{array}{l}\text { Visuals print } \\
\text { advertisement }\end{array}$ & Trackyour & $\begin{array}{l}\text { Younger carer } \\
\text { Older women } \\
\text { Children, pets, } \\
\text { possessions }\end{array}$ & $\begin{array}{l}\text { Lost/Wandering } \\
\text { Withdrawn and call } \\
\text { for care } \\
\text { Fallen } \\
\text { Smiling } \\
\text { Actively living well }\end{array}$ \\
\hline 5 & Z & $\begin{array}{l}\text { Visuals print } \\
\text { advertisement }\end{array}$ & Spotter & $\begin{array}{l}\text { Younger carer } \\
\text { Older women } \\
\text { Children, pets, } \\
\text { possessions }\end{array}$ & $\begin{array}{l}\text { Smiling } \\
\text { Actively living well }\end{array}$ \\
\hline
\end{tabular}

\footnotetext{
${ }^{1}$ The Dutch brand name "VeiligOudKaart" has been literally translated into English.

${ }^{2}$ The Dutch brand name "Zorgriem" has been literally translated into English.
} 


\begin{tabular}{|l|l|l|l|l|l|}
\hline & & Visuals print & Stray Star & Younger carer & Lost/Wandering \\
advertisement & & Older women & Withdrawn \\
Older male & Call for constant care \\
& & & & Children, pets, & Fallen \\
& & & possessions & Terrible destiny \\
& & & & awaits \\
& & & & Smiling \\
& & & & Actively living well \\
\hline
\end{tabular}

Table 2 presents an overview of the dichotomous categories present in the sample.

Some advertisements include positive representations of (predominantly) women with dementia who are depicted smiling, actively living well and kept safe through using ST.

However, the majority of the advertisements include negative representations of (predominantly) females with dementia. They are signalled as lost, wandering, withdrawn, and calling for constant care because they should be kept safe through using ST. Similar to Vermeer, et al. (2019a), these technologies simultaneously target tracking pets and possessions through visuals and texts which seem to be directed at carers. Accordingly, categories of gender signal how younger carers are responsible for taking care of the older women. Further, privacy or autonomy concerns and who receives the data from the ST (e.g. tech companies, alarm centres, other family members) is not addressed. Rather, text often describe small ST to covert-track someone's location. While one advertisement describes a person with dementia using technology, the majority seem to visually "place" the ST on people living with dementia, or the technology is not shown at all. Hereby, the dominant theme shows a "wanderer" discourse which stresses keeping the person with dementia safe through ST without acknowledging them as human technology users. What signs are used to communicate this theme to audiences is described in the following section. 


\section{Youtube film SafetyOldCard}

The Dutch organisation behind the film SafetyOldCard was no longer active in June 2019. Nonetheless, their YouTube channel continued to circulate the film. The text describes: "Do you have a parent who lives alone, or do you live alone, afraid not being able to reach the phone or does your loved one wander because of dementia? This is the solution because it is easy to use, four buttons, SOS-button, low purchase price and cheap". The channel describes the product as small and easily worn around the neck. The film shows the product which looks like a bank card. Later visuals are shown of Caucasian older adults who look withdrawn out of a window, have fallen or may be lost. The text seems to be addressing carers and those who are in need of care but the visuals indicate that the latter are not the intended target audience. Rather, the visuals in combination with keywords such as "wandering" and "afraid" makes a discourse of a terrible destiny that awaits if technology is not used.

\section{Youtube film The family}

Wittra, based in Sweden and founded in 2013, circulated the film on YouTube. According to LinkedIn, this small-sized organisation shows an increase in the number of employees and products on sale from 2017 to 2019, whilst other publicly available information shows a decrease in profits (UC Allabolag AB 2019). The first scene shows a blonde male actor who directly gazes into the camera. Hesits between two withdrawn brown-haired actors. The brown-haired actors seem to be in their thirties. The blonde male actor says, 'These guys decided they needed a little help organizing things and who can blame them'. While the two actors remain parallel to that of the viewer, the blonde actor speaks to the audience 'the important things in life are the things that we 
care about. They move around making them even harder to keep track on ... well that's where I come in". The use of "we" and "I" are connotations for allowing the audience into the world where families need support tracking moving things. Moving things such as "DOGS impossible to understand even harder to keep track of. I'm Tagged and it's my job to keep this family safe and sound". The blonde actor's diminutive name signifies him as being the ST. Later Tagged is sitting and leaning over a grey haired actress, who in turn, seems to be unaware of his presence. He says "let me show you grandma in her favourite chair but sometimes she can get a little [whistle sound] bit lost if you know what I mean". The signified meaning when Tagged makes a hand gesture with a whistling sound indicates grandma as a bit crazy who needs to be looked after. These signs represent that the technology will keep grandma safe. The next scene signifies a white furry dog with Tagged saying "I'm on it". Seconds later, we see the male family member looking on his mobile phone and finding the dog. Later the female family member places a baby in a crib. The signified meaning forms her as a motherfigure. Tagged watches over and says: “Relax I'm on it. Think of me as the guy who's always there watching every move sitting next to your sleeping baby --- errr not in a weird way". The mother opens the app on her phone, walks away and when the baby cries Tagged says " a little help!". The mother returns looks at the app and bends over the crib. The combination of signifier and signified present the meaning that mom is supported in her caring role when the baby is monitored by using the technology.

The next scene shows grandma walking and looking distanced in the woods. Tagged says "oh grandma... so you get the point, right. If you put me on it you'll know what's happening and where it's happening... safe and sound". The signs that grandma tends to get lost and is vulnerable might be a search for sympathy and empathy from carers who can relate to having one's care recipient lost. The final scene quickly shows 
the product, icons and the text; "pets, baby watch, bag safety, elder, bike safety, car alarm, smoke detector, key camera". It suggests the safeguarding of certain categories. Noteworthy is that the first-person pronouns are recurrent, with "I" conveying an individual identity and "you" refers to the viewer. The language focusses on the individual without acknowledging the company, which implies a customer-oriented attitude.

\section{Youtube film Carebelt}

This film was circulated on Youtube and broadcasted multiple times on Dutch television. It was also placed on the brand's website, which is part of the mother company MobileTrack based in the Netherlands. It is unclear when MobileTrack established the Carebelt however, press releases date back to 2008 (MobileTrack 2008). The Carebelt was considered a 'cottage industry' in 2017, but the number of employees listed on LinkedIn had increased in 2019, making it a small-sized company. The brand's diminutive name signifies that the ST is to be worn on a belt. The first scene states "find the person immediately”. Signifiers in the next scene show a grey-haired man behind his window who seems withdrawn and gazes outside. Then a male narrator voice starts with; This is Mr van Dijk, 62 years old. In the past year, he increasingly had problems with memory loss. The actor starts walking in his house and the viewer sees a portrait of a woman. The narrator says: He lives together with his wife Truus in a village. The actor grabs his keys and another device is shown which looks like a mobile phone with a few large buttons. When he presses a button, the device is activated. As we see the actor leaving the house the narrator says: He carries his mobile GPS-alarm system that monitors your location. Relaxed as he is walking now... this has not always been the case. He cannot orientate and that is why he gets lost. Suddenly, the actor's facial 
expression shows uncertainty and the switching between the scenes increases and the music becomes intense. The narrator continues: That caused a lot of tension and he became insecure. When the narrator says "tension" the camera angle goes from left to right. It is as if the audience sees through the eyes of the actor experiencing tension. The actor looks from left to right and the narrator says: luckily, he now has his mobile GPSalarm system with him. When the actor presses the "SOS" button and tries to phone, the narrator says; it gives him confidence, especially when he suddenly doesn't know which direction to take. A woman in her late thirties answers the phone and in the system, she sees his location.

\section{Mr van Dijk: I'm not sure where I am. Can you give me directions to go back? \\ Alarm-centre responder: Do you see a street sign behind you?}

The responder gives walking directions and when the actor starts walking, the narrator says:

Thanks to modern technology, he can go outside independently and if he is lost, there will always be a friendly employee that will guide him home safely.

The final scene shows the actor together with the text: "Thanks to my mobile alarm system I'll never get lost again" and ends with "quality of life". The narrator describes how surveillance can help families in various ways in order to make an emotional connection with consumers. An emotional connection such as fear of becoming lost and the need for surveillance.

Visuals print advertisement Carebelt

However, the film did not portray that the product should be worn on a belt, the website 
includes visuals of the ST attached to a belt. The website also includes a visual of an older woman who grabs her coat and looks scared whilst in the background a group of young males with dark hoodies on, are pointing at her. Although the text described "monitor your loved one", the woman is signalled to be in danger.

\section{Visuals print advertisement TrackYour}

The organisation TrackYour was established in 2012 in the UK. According to Linkedin and Companies House public beta service (2019), the organisation matured from a cottage industry in 2017 (e.g. one employee no physical office) into a small company in 2019 (two shareholders and a registered office) but the annual summary shows a loss in income. The website includes texts such as "wandering" , "peace of mind", "retaining their independence" and "FREE". In bullet points, the website describes product features and how small and conceivable the ST is. The diminutive brand name signals tracking, the logo of the band signified visual stereotypes through icons of a child, an older adult with a walking stick and a dog. In a circle, a female in her twenties is smiling and leaning on the shoulder of an older woman in her seventies. The younger female caresses the shoulder of the older woman indicating that the former is a family member and/or carer. The older woman (e.g. white hair, wrinkles) is smiling and the product is shown with a SOS-button. Furthermore, four boxes show a girl, an older woman, a dog and a businessman standing next to a car with suitcases. The website states "people, pets \& possessions", which is accompanied by typical stock photos found on many websites selling ST (Harvey and Brookes 2018; Vermeer et al. 2019a). Another webpage contains an emotional narrated story through words such as "being separated from your loved one" and "out and about is everyone's worst nightmare". This indicates that the text is targeted at family members. Similar stock images are 
shown, such as happy children, older women smiling and a younger female. Another page includes an older woman who lies on the floor and looks distressed and presses the SOS-button. It appears she has fallen and is in danger and the text described how the technology helps them.

\section{Visuals print advertisement Spotter}

The organisation behind the diminutive brand name Spotter is based in the Netherlands and established in 2015. According to LinkedIn, the organisation grew from a smallmedium company (e.g. max 50 employees) in 2017 into a medium company (e.g. 50 to 200 employees) in 2019. However, other public information shows how the subsidiary organisation only has nine employees and is part of a mother company owned by one person, whom in turn, is not obliged to share financial statements to the public (Kompass 2019; KVK 2019). The website describes how their small product is the GPS tracker for dementia indicative of presenting it as the solution. The visuals represent female carers in their thirties and older women in their seventies who are smiling and actively living well with keywords as signifiers. The website shows a generic stockphoto of an older woman and signified categories of tracking children, pets and possessions which are kept safe by using the product.

\section{Visuals print advertisement Stray Star}

Stray Star LTD based in the UK shows a decrease from 2017 to 2018 in capital and reserves (Companies House public beta service 2019). LinkedIn lists zero employees, which is the responsibility and choice of the company to present this information to the public. The website includes keywords together with representations of younger carers 
in their twenties and thirties, older women in their seventies and the categories of track children, pets and possessions. The webpage dementia trackers states "essential for peace of mind" and signifies actors as lost, wandering, looking withdrawn, or fallen down beneath a stairwell. Hence, a terrible destiny awaits if surveillance is not used. These visuals are stock-photos, which can be found on numerous websites. The elderly tracker and fall webpages, show an older man walking with a walking stick but also older couples holding each other and smiling. The text describes how fall detectors will not reduce the risk of falling, whereas, the dementia webpage describe the ST as "the best dementia trackers on the market - a simple great solution, offering reassurance and convenience in being able to find your loved one quickly".

\section{Audience responses}

Table 3 audience response

\begin{tabular}{|c|c|}
\hline Discourse & Audience response \\
\hline Youtube films & $\begin{array}{l}\text { Participants do not understand it } \\
\text { - Negotiation }\end{array}$ \\
\hline $\begin{array}{l}\text { Visuals print } \\
\text { advertisements }\end{array}$ & $\begin{array}{l}\text { - Negotiation (carers) } \\
\text { - Opposition (people living with dementia) }\end{array}$ \\
\hline
\end{tabular}

Table 3 describes how participants responded to the films and later the visuals. The initial reaction was that the participants did not understand the films. The carers did not receive the meaning that Tagged is the technology. As a result, the carers started negotiating and questioning what the product is supposed to look like and what it does with regards to functionality.

Carer: I don't understand how the products look like Carer2: yes something with a phone but how does it work? Carer3: that was a camera that you can hang around the house

Carer4: but also in the forest? Carer3: Grandma is carrying that one. Right?

[The family] 
The carers described how the film did not make any sense and led discussion back to what they are looking for in a small tracker for safety reasons. In particular, the carers explained that they type their need for a small covert ST into Google. Furthermore, people living with dementia described how frustrated it made them feel to watch the films, which according to them were too fast in pace and provided little information on what the product does. They agreed that especially the film SafetyOldCard was difficult to follow and to understand.

\section{Researcher: does anyone know what's it about? PWD1: too fast, too much text PWD2: No clue PWD3: at some point I saw that telephone [SafetyOldCard]}

Participants did receive the message that the lost actor used the Carebelt and found his way back home. Despite the diminutive brand name, the carers asked whether the Carebelt should be worn on a belt and did not understand product functionalities. They negotiated the film by describing how a person with dementia is unable to remember to carry such a product or call the alarm-centre.

\section{Carer1: so it isn't a belt?}

Carer4: but if it's a belt he needs to wear it

[Carebelt]

People living with dementia continued to negotiate the film by discussing technologies they can use and which they cannot. Even though one person with dementia was content with the Carebelt, the others negotiated the usefulness of the technology by asking questions about how it would work in their situation. 


\author{
PWD2: YES amazing \\ PWD1: but what's that supposed to be? \\ PWD2: a belt for on your pants \\ PWD1: oooh \\ [Carebelt]
}

Some participants with dementia could relate to the experience of walking outside and forgetting how to walk back home. However, they did not understand how the product works and others thought it was all contradictory. The issue was raised that producers do not make useful technologies for people living with dementia.

PWD2: then he remembered again [when the actors calls the alarm centre] but during the film I thought this is terribly contradictory. I have it and I succeeded to walk with the help of my smart phone. But even that I don't have anymore. But with this film its all contradictory... that you call and the alarm centre gives you directions

PWD1: there is someone who is asking questions like oh you're there... that's where you need to cross the corner. I think that's pretty smart but what's the use of a smart phone? Then I need to know how to get that thing started.

[Carebelt]

PWD1: I don't agree with having solutions for problems that aren't smart things. Everyone should be able to use it. I think this all is very complicated.

[SafetyOldCard]

Visuals

The participants had different views about the visuals. The carers negotiated the visuals, for example, by expressing their liking for the diversity of representations used, whereas other carers found the categories of tracking dogs and people living with dementia "a bit too much". Although participants picked up on the use of positive and negative representations in the advertisements, the carers described how such visuals do not 
influence them to buy the product. They explained that their focus is on what the product does and moved the conversation about their daily struggles with caregiving.

Carer2: that film shows more diversity. Not just old people with walking sticks. I did this dementia-friendly e-learning and they use good images instead of just really old people. They use representations of an active grandma that is picking up her grandchildren from school

[The family]

Researcher: is it that you think oh this commercial is showing a lost person with dementia and therefore I want to buy this product?

Carers: no!

Carer2: No I just type in google GPS tracker small unnoticeable and look for that.

These responses were different from the participants living with dementia who became frustrated when seeing the visuals and being compared to pets.

$$
\text { PWD1: I don't want to be compared to a dog }
$$

This frustration became more apparent when they discussed the negative representations and started interrupting each other or raising their voice.

PWD5: What happens here is that they show the worst-case scenario but there are so many things happening before. I don't recognise myself in it.

PWD1: I think if you want to make something clear then this isn't the right image.

PWD5: but I don't think there's an image for that. There's no label you can tape on your forehead because everyone is so different.

When the researcher asked how people living with dementia would like to be portrayed in the media there was no consensus. Some participants with dementia thought positive representations would be better compared to negative representations. However, others described they just want to see the reality of what it is like to live with dementia. 
Alzheimer Nederland: you just said you will lose your freedom and that it makes you happy if they show you something that will increase your independence?

PWD5: yes

Alzheimer Nederland: that's something you would prefer over negative?

PWD5: well yes but I also understand there is a lack of understanding and people do not have any experience with dementia, so I get that this can happen, but you're more than just your disease. It's just a tricky disability... I can live well with it by the way

\section{Discussion}

This study set out with the objective of considering the ways advertisements represent dementia in technology advertisements and how carers and people living with dementia respond. It does so through a qualitative tripartite approach, however it does not provide unquestionable results about the organisations behind these websites. Some organisations seem to grow with regards to the numbers of employees, but a decrease in capital. Although, a normal part of growing in business is to expand in employee size as human capital is a valuable resource which costs capital (Chung-Jen Chen and JingWen Huang 2009).

The examination of representations provides grounds, however, for the charge of rampant, if largely unintended, stereotyping. The advertisements wish to speak to the ideal user through typical stock-photos of younger female carers and text descriptions targeted at them. Minimum representations were given of people living with dementia interacting with technology, but their viewpoints and those of different ethnic cultural groups were omitted. These findings support the idea that the voices from people living with dementia are excluded while low-cost stock photos show female carers and focus 
on the dangers of dementia (Clarke, 2006; Harvey and Brookes, 2018). This

corroborates the idea that ST are designed for (younger) female carers and that people living with dementia (particularly older women) are not the intended user (Brankaert 2016; Joyce and Mamo 2006). This might be explained by the large debate about how advertisers neglect older consumers, both in the market they target and the actors they depict in advertisements (Corlett 1998). Advertisers recommend including female actors in their thirties to target women consumers in their forties (Financial Times 2014). The idea is that consumers in their forties (those who are likely to have parents with dementia) feel cognitively younger than their chronological age and would relate more to younger actors which influences purchase decisions (Schiffman and Sherman 1991; Barak 1987; Stephens 1991). The effectiveness of this influence, however, has been challenged in research (Greco et al. 1997; Mazis et al. 1992).

An important consequence of this study is that there is not one unitary way of understanding or interpreting the advertisements for dementia. Rather, participants did not understand the advertisements or the displayed technology and some became frustrated for not understanding these meanings. This is similar to Dobos and colleagues (2015) who reported that the ambiguity in visual imagery is not a surprise. Even though there was no consistent response from the audience, the participants noticed the use of positive and negative representations. The carers negotiated how the advertisements did not influence their purchase decision because they look for product functionalities, in contrast to participants living with dementia who negotiated the films and thought ST are not so useful products for people living with dementia. They opposed the visuals with agitation and thought it was offensive and stigmatising. That people living with dementia were more noticeably impacted compared to carers is not surprising given that the negative representations try to represent them and their disease. 
The dissemination of negative representations is not the only concern, rather its shows a lack of reflexivity from marketers who do not realise that people living with dementia are not objects. Similar to previous findings, a "wandering discourse" where people living with dementia are placed in the same category as pets and possessions in need of covert tracking is both insulting and will not change technology development (Vermeer et al. 2019a). Rather, the current display of people living with dementia as non-human technology users enhances stigma which might negatively affect personhood and prevent empowerment.

Accordingly, the intended consumers, who are the carers expressed their need for a conceivable ST. They also liked the diversity of representations in the advertisements used even though similar Caucasian actors were shown. This insinuates that audiences (unconsciously) accept certain meanings that might contain ideologies and indicate complex power relations. These messages corroborate with Hall's (1980) concern of media power and how it propagates certain social values to create dominant ideologies, which will ultimately influence audiences to construct this as the truth.

Therefore, this study is not directed at website providers alone but also those who design technology and media that represent people living with dementia. Similar to recommendations from Harvey and Brookes (2018), it is important for researchers, media developers and policymakers to be conscious of the power within dementia discourses that shape public understandings and perceptions. This leads inexorably to questioning if non-stigmatising representations are fathomable or culturally possible. Hence, more research is necessary on representations of dementia that offer some hope and allay support for people living with dementia and carers.

However, the approach and small sample must be interpreted with caution as the 
findings might not be transferable to other advertisements or representations. Even though it was not the intention to study a large sample, it is through the use of these keywords that organisation's draw visitors to their websites and consequently see these advertisements (Patrutiu-Baltes 2016). 89 percent of consumers turn to Google and type in these words. Search Engine Optimization techniques then position the providers website to be the first on display according to these keywords (Fleishman and Hillard 2012; Patrutiu-Baltes 2016). Furthermore, the results about providers should be taken cautiously as they are often not obliged to publicize such information to the public. An issue that was not addressed in this study was whether Dutch participants would respond differently towards advertisements originating from another country. Therefore, it would be useful to investigate a larger sample of organisations that disseminate discourses about dementia and ST and to understand their reasoning behind the decisions of these discourses and whether or not they are successful financially. In addition, a future study investigating the differences in participants' background (e.g. culture, gender) would be interesting.

\section{Conclusion}

This study found a "wanderer" discourse evident in much of the advertisements which signals to covertly use simple trackers on people living with dementia. The advertisements sketch stories of how families are in need of surveillance through making an emotional connection with female carers. This emotional connection is established through exacerbating fear by signs of possessions, children, pets and the person with dementia not being safe, whereby text signifies a problem in terms of concern and distress combined with visuals which signify a conceivable location monitor as the ideal solution. However, carers and people living with dementia did not 
understood the advertisements and the displayed technology. Instead, people living with dementia felt stigmatised. It is not just that negative representations are disseminated, but the lack of reflexivity from designers and marketers when they see people living with dementia as objects. This study believes that by solely relying on stereotypes targeted at carers with misunderstood conceivable technology hinders resilience for people living with dementia and implies the continuous stigmatisation that occurs when they are disregarded as human technology users.

\section{References}

Akrich, Madeleine. 1992. "The De-Scription of Technical Objects." In Shaping Technology/Building Society: Studies in Sociotechnical Change., e. Cambridge, MA: MIT Press.

Alzheimer's Association. 2008. "Wandering: Who's at risk?". Alzheimer's Association. Retrieved from http ://www.alz.org/national documents/ card_wanderingwhoisatrisk. pdf Accessed 25 March 2020.

Barak, Benny. 1987. "Cognitive Age: A New Multidimensional Approach to Measuring Age Identity." International Journal of Aging and Human Development 25 (2): 109-28.

Birt, Linda, Poland, Fiona., Csipke, Emese., \& Charlesworth, Georgina. 2017. Shifting dementia discourses from deficit to active citizenship. Sociology of Health \& Illness, 39(2), 199-211.

Bosco, Alessandro., Schneider, Justine., Coleston-Shields, Donna Maria., Higgs, Paul, \& Orrell, Martin. 2019. The social construction of dementia: Systematic review and metacognitive model of enculturation. Maturitas, 120, 12-22.

Brankaert, Rens. 2016. "Design for Dementia : A Design-Driven Living Lab Approach to Involve People living with dementia" PhD diss., TU Eindhoven.

Braun, Virginia, and Victoria Clarke. 2006. "Using Thematic Analysis in Psychology." Qualitative Research in Psychology 3 (2): 77-101.

Brookes, Gavin, Kevin Harvey, Neil Chadborn, and Tom Dening. 2018. "“'Our biggest killer": multimodal discourse representations of dementia in the British press." Social Semiotics 28 (3): 371-395.

Carr, Dawn, Glenn W. Muschert, Jennifer Kinney, Emily Robbins, Gina Petonito, Lydia Manning, and J. Scott Brown. 2010. "Silver Alerts and the Problem of Missing Adults with Dementia." Gerontologist 50 (2): 149-57.

Chung-Jen Chen, and Jing-Wen Huang. 2009. "Strategic Human Resource Practices and Innovation Performance - The Mediating Role of Knowledge Management Capacity." Journal of Business Research 62 (104 114).

Clarke, Juanne N. 2006. "The Case of the Missing Person: Alzheimer's Disease in Mass Print Magazines 1991-2001." Health Communication 19 (3): 269-76.

Companies House public beta service. 2019a. "Companies House Public Beta Service Track Your.” GOV.uk. https://beta.companieshouse.gov.uk/. Accessed June 1, 2019. 
Deep. 2013. "Collecting the Views of People living with dementia." https://www.dementiavoices.org.uk/wp-content/uploads/2013/11/DEEP-GuideCollecting-views.pdf. (accessed January 19, 2017).

Dobos, Amy R., Lindy A. Orthia, and Rod Lamberts. 2015. "Does a Picture Tell a Thousand Words? The Uses of Digitally Produced, Multimodal Pictures for Communicating Information about Alzheimer's Disease." Public Understanding of Science 24 (6): 712-30.

Downe-Wamboldt, Barbara. 1992. "Content Analysis: Method, Applications, and Issues." Health Care for Women International 13 (3): 313-21.

Financial Times. 2014. “Advertisers' Ageing Dilemma." October 29, 2014. 2014. https://www.ft.com/content/7bb881d2-5915-11e4-9546-00144feab7de. (accessed July 19, 2019).

Fleishman and Hillard. 2012. "Understanding the Role of the Internet in the Lives of Consumers." 2012 Digital Influence Index Annual Global Study. St Louis.

Fuller, C. 1998. Caring for Profit: How Corporations Are Taking over Canada's Health Care System. Vancouver: New Star Books.

Gorp, Baldwin Van, and Tom Vercruysse. 2012. "Frames and Counter-Frames Giving Meaning to Dementia: A Framing Analysis of Media Content." Social Science and Medicine 74 (8): 1274-81.

Greco, Alan J., Linda E. Swayne, and Edna B. Johnson. 1997. "Will Older Models Turn off Shoppers?" International Journal of Advertising 16 (1): 27-36.

Hall, Stuart. 1980. "Encoding/Decoding. " Edited by Centre for Contemporary Cultural Studies, S Hall, D Hobson, A Lowe, and P Willis. Culture, Media, Language. London: Hutchinson.

Harman, Guy. and Clare, Linda., 2006. Illness representations and lived experience in early-stage dementia. Qualitative health research, 16(4), 484-502.

Harvey, Kevin, and Gavin Brookes. 2018. "Looking Through Dementia: What Do Commercial Stock Images Tell Us About Aging and Cognitive Decline?" Qualitative Health Research, December, 104973231881454.

INDUCT 2019, "Best practice guidance human interaction with technology in dementia", available at

www.dementiainduct.eu/guidance/ . Accessed 31 January 2020.

Joyce, Kelly, and Laura. Mamo. 2006. "Graying the Cyborg; New Directions in Feminist Analyses of Aging, Science, and Technology." In Age Matters Realigning Feminist Thinking, edited by T.M. Calasanti and K.F. Slevin. New York, London: : Taylor and Francis Group; Routledge.

Joyce, K, M Loe, L Diamond-Brown - 2015. "Science, Technology and Aging." In Routledge Handbook of Cultural Gerontology, edited by J Twigg and W Martin, 157-64. London.

Kellner, Douglas, and Jeff Share. 2007. "Critical Media Literacy, Democracy, and the Reconstruction of Education." Media Literacy: A Reader. https://www.researchgate.net/profile/Jeff_Share/publication/237225853_Critical _Media_Literacy_Democracy_and_the_Reconstruction_of_Education/links/02e 7e52cb8789f2570000000.pdf. Accessed 25 May 2017

Kenner, Alison Marie. 2008. "Securing the Elderly Body: Dementia, Surveillance, and the Politics of "Aging in Place." Surveillance \& Society 5 (3): 252-69.

Kessler, Eva Marie, and Clemens Schwender. 2012. "Giving Dementia a Face? The Portrayal of Older People living with dementia in German Weekly News 
Magazines between the Years 2000 and 2009." Journals of Gerontology - Series B Psychological Sciences and Social Sciences 67 B (2): 261-70.

Kompass. 2019. "Spotter B.v. Bergschenhoek 2661 CZ (Lansingerland), Leeuwenhoekweg 20 C , KVK NUMMER 62825518.” July 2019. https://nl.kompass.com/c/spotter-b-v/nln2859100/. Accessed July 20, 2019.

KVK. 2019. "Wel of Niet Deponeren?" [To deposit or not?] June 2019. 2019. https://www.kvk.nl/inschrijven-en-wijzigen/deponeren/jaarrekeningdeponeren/wel-of-niet-deponeren/.Accessed June 11, 2019.

Latour, Bruno. 1992. "Where Are the Missing Masses? The Sociology of a Few Mundane Artifacts." In Shaping Technology / Building Society, edited by W Bijker and J Law, 225-58. Cambridge, MA: MIT Press.

Lewis, Justin, and Sut Jhally. 1998. "The Struggle over Media Literacy.” Journal of Communication 48 (1): 109-20.

Lincoln, Yvonna S, and Egon G Guba. 1985. Naturalistic Inquiry. 75th ed. Sage Publications Ltd.

Loos, Eugène, and Loredana Ivan. 2018. "Visual Ageism in the Media." In Contemporary Perspectives on Ageism., 163-76. Springer, Cham.

Machin, David. 2004. "Building the World's Visual Language: The Increasing Global Importance of Image Banks in Corporate Media." Visual Communication 3 (3): 316-36.

Mazis, Michael B., Debra Jones Ringold, Elgin S. Perry, and Daniel W. Denman. 1992. "Perceived Age and Attractiveness of Models in Cigarette Advertisements." Journal of Marketing 56 (1): 22-37.

McCabe, Louise, and Anthea Innes. 2013. "Supporting Safe Walking for People living with dementia: User Participation in the Development of New Technology." Gerontechnology 12 (1): 4-15.

McParland, Patricia, Fiona Kelly, and Anthea Innes. 2017. "Dichotomising dementia: is there another way?." Sociology of health \& illness 39, (2): 258-269.

Medina, Raquel. 2014. "From the Medicalisation of Dementia to the Politics of Memory and Identity in Three Spanish Documentary Films: Bicicleta, Cullera, Poma, Las Voces de La Memoria And." Ageing \& Society 34 (10): 1688-1710.

Minichiello, Victor, Jan Browne, and Hal Kendig. 2000. "Perceptions and Consequences of Ageism: Views of Older People." Ageing and Society 20 (3): 253-78.

MobileTrack. 2008. "MobileTrack GPS Oplossingen Voor Het Lokaliseren van Alzheimer Dementie Cliënten Wetenschappelijk Onderzocht [Mobiletrack GPS solutions to locate Alzheimer Dementia Clients researched]." 15 December 2008. https://www.mobiletrack.nl/persberichten/mobiletrack-gps-oplossingenvoor-het-lokaliseren-van-alzheimer-dementie-clienten-wetenschappelijkonderzocht/. (last accessed June 16, 2019).

Mooij, Marieke De. 2004. "Translating Advertising: Painting the Tip of an Iceberg." Translator 10 (2): 179-98.

Neven, Louis. 2010. "'But Obviously Not for Me': Robots, Laboratories and the Defiant Identity of Elder Test Users." Sociology of Health \& Illness 32 (2): 33547.

Niemeijer, Allistair. R. 2015. "Exploring Good Care with Surveillance Technology in Residential Care for Vulnerable People." PhD Diss. VU University Press.

Patrutiu-Baltes, Loredana. 2016. "Inbound Marketing - the Most Important Digital Marketing Strategy." Bulletin of the Transilvania University of Brasov. Series V: Economic Sciences 9 (2): 690-700. 
Peel, Elizabeth. 2013. “'The Living Death of Alzheimer's' versus 'Take a Walk to Keep Dementia at Bay': Representations of Dementia in Print Media and Carer Discourse." Sociology of Health \& Illness 36 (6): 885-901.

Petonito, Gina., Glenn. W. Muschert, and Tirth. Bhatta. 2010. "Between Caring and Control: The Emergence of Silver Alert Systems to Locate Missing Elders with Dementia." In Meetings of the American Sociological Association. Atlanta, GA.

Rasquin, Sascha M C, Charles Willems, S de Vlieger, R P J Geers, and Mathijs Soede. 2007. "The Use of Technical Devices to Support Outdoor Mobility of Dementia Patients." Technology and Disability 19 (2): 113-20.

Rose, Gillian. 2007. Researching Visual Materials: Towards a Critical Visual Methodology. Visual Methodologies. An Introduction to Interpreting Visual Materials. London: Sage Publications Ltd.

Rowe, Meredeth A., and Judith C. Glover. 2001 "Antecedents, descriptions and consequences of wandering in cognitively-impaired adults and the Safe Return (SR) program." American Journal of Alzheimer's Disease \& Other Dementias ${ }^{\circledR}$ 16 , no. 6 344-352.

Rowe, Meredeth A. 2003 "People with Dementia Who Become Lost: Preventing injuries and death." AJN The American Journal of Nursing 103, no. 7: 3239.Saussure, F De. 2011. Course in General Linguistics. Edited by P Meisel and H Saussy. New York: Columbia University Press.

Schiffman, Leon G., and Elaine Sherman. 1991. "Value Orientations of New-Age Elderly: The Coming of an Ageless Market." Journal of Business Research 22 (2): 187-94.

Stephens, Nancy. 1991. “Cognitive Age: A Useful Concept for Advertising?” Journal of Advertising 20 (4): 37-48.

Stray Star 2019. "STRAY STAR LTD - Filing History (Free Information from Companies House).” 2019. 2019. https://beta.companieshouse.gov.uk/company/08469000/filing-history (last accessed June 15, 2019).

Sweeting, Helen, and Mary Gilhooly. 1997. "Dementia and the Phenomenon of Social Death." Sociology of Health \& Illness 19 (1): 93-117.

Swinnen, Aagje., \& Schweda, Mark. 2015. Popularizing dementia. Public Expressions and Representations of Forgetfulness. Bielefeld: Transcript Verlag, 9-20.

Thoman, Elizabeth., and Tessa. Jolls. 2005. "Literacy for the 21st Century: An Overview \& Orientation Guide to Media Literacy Education." Vol. d.

UC Allabolag AB. 2019. “Allabolag”[All companies] Sweden. https://www.allabolag.se/ (last accessed June 15, 2019).

Vermeer, Yvette, Paul Higgs, and Georgina Charlesworth. 2019a. "Marketing of Surveillance Technology in Three Ageing Countries." Quality in Ageing and Older-adults 20 (1): 20-33

Vermeer, Yvette, Paul Higgs, and Georgina Charlesworth. 2019b. "Surveillance Technology in Dementia Care: Implicit Assumptions and Unresolved Tensions". In Dementia Lab Conference . 101-113. Springer, Cham. https://doi.org/10.1007/978-3-030-33540-3_10

Vermeer, Yvette, Paul Higgs, and Georgina Charlesworth. 2019c. "What do we require from surveillance technology? A review of the needs of people with dementia and informal caregivers. Journal of Rehabilitation and Assistive Technologies Engineering. (6), 1-12 https://doi.org/10.1177/2055668319869517 
Vermeer, Yvette, Paul Higgs, and Georgina Charlesworth. 2020a. "People with dementia and carers online discussing surveillance". Journal of enabling technologies. In print.

Vermeer, Yvette, Paul Higgs, and Georgina Charlesworth. 2020b. "Audience reception to advertising of Surveillance Technology in dementia: evidence from focus groups" Ageing and Society. Forthcoming

Vulpe, Simona. N. 2017. "From Sick Elderly to Super-Grandparents. A Typology of Elderly Representations in Romanian Video Advertising." Journal of Comparative Research in Anthropology and Sociology 8 (2): 115-48.

Zeilig, Hannah. 2014. "Dementia as a Cultural Metaphor." Gerontologist 54 (2): 25867. 